\title{
MULTILINEAR HAUSDORFF OPERATOR AND COMMUTATORS ON WEIGHTED MORREY AND HERZ SPACES
}

\author{
DAO VAN DUONG* AND NGO THI HONG
}

\begin{abstract}
In this paper, we establish some necessary and sufficient conditions for the boundedness of multilinear Hausdorff operators on weighted central Morrey and Herz type spaces. Moreover, we also discuss some sufficient conditions for the boundedness of commutators of multilinear Hausdorff operators on weighted Morrey-Herz spaces. By these, we generalize some previous known results.
\end{abstract}

Mathematics subject classification (2020): 42B35, 46E30, 47B38.

Keywords and phrases: Multilinear operator, Hausdorff operator, Hardy operator, Morrey spaces, Herz spaces, commutators.

\section{REFERENCES}

[1] K. F. ANDERSEN, Boundedness of Hausdorff operators on $L^{p}\left(\mathbb{R}^{n}\right), H^{1}\left(\mathbb{R}^{n}\right)$, and $B M O\left(\mathbb{R}^{n}\right)$, Acta Sci. Math. (Szeged), 69 (2003), 409-418.

[2] R. BANDALIYeV AND P. GóRKA, Hausdorffoperator in Lebesgue spaces, Math. Inequal. Appl. 22(2) (2019), 657-676.

[3] R. Bandaliyev And K. SAFarova, On boundedness of multidimensional Hausdorff operator in weighted Lebesgue spaces, Tbilisi Math. J. 13 (2020), 39-45.

[4] G. BRown AND F. MóRICZ, Multivariate Hausdorff operators on the spaces $L^{p}\left(\mathbb{R}^{n}\right)$, J. Math. Anal. Appl. 271 (2002), 443-454.

[5] V. I. BuRENKov And E. LiflyAnd, Hausdorff operators on Morrey-type spaces, Kyoto J. Math. 60 (2020), 93-106.

[6] R. R. COIFMAn, R. Rochberg AND G. Weiss, Factorization theorems for Hardy spaces in several variables, Ann. Math. 103 (1976), 611-635.

[7] N. M. Chuong, Pseudodifferential operators and wavelets over real and p-adic fields, Springer-Basel (2018).

[8] N. M. Chuong, D. V. Duong And K. H. Dung, Two-weighted inequalities for Hausdorff operators in Herz-type Hardy spaces, Math. Notes 106 (2019), 20-37.

[9] N. M. Chuong, D. V. Duong And K. H. Dung, Multilinear Hausdorff operator on variable exponent Morrey-Herz type spaces, Integral Transforms Spec. Funct. 31 (2020), 62-86.

[10] N. M. Chuong, D. V. Duong And N. D. DuYet, Weighted Morrey-Herz space estimates for rough Hausdorff operator and its commutators, J. Pseudo-Differ. Oper. Appl. 11 (2020), 753-787.

[11] N. M. Chuong, D. V. Duong And N. D. Duyet, Two-weighted estimates for multilinear Hausdorff operators on the Morrey-Herz spaces, Adv. Oper. Theory 5 (4) (2020), 1780-1813.

[12] N. M. Chuong, N. T. Hong And H. D. Hung, Multilinear Hardy-Cesàro operator and commutator on the product of Morrey-Herz spaces, Anal. Math. 43 (2017), 547-565.

[13] N. M. Chuong, D. V. Duong And H. D. Hung, Bounds for the weighted Hardy-Cesàro operator and its commutator on Morrey-Herz type spaces, Z. Anal. Anwend. 35 (2016), 489-504.

[14] C. Carton-Lebrun And M. Fosset, Moyennes et quotients de Taylor dans BMO, Bull. Soc. Roy. Sci. Liége 53 (1984), 85-87.

[15] D. V. DUONG, K. H. DUNG AND N. M. CHUONG, Weighted estimates for commutators of multilinear Hausdorff operators on variable exponent Morrey-Herz type spaces, Czechoslovak Math. J. 70 (2020), $833-865$ 
[16] D. V. Duong, Hausdorff operator and commutator on weighted Morrey-Herz spaces on p-adic fields, Anal. Math. Physics 11:31 (2021).

[17] J. Chen, D. FAn And J. Li, Hausdorff operators on function space, Chin. Ann. Math, Series B 33 (2012), 537-556.

[18] R. R. Goldberg, Convolutions and general transforms on $L^{p}$, Duke Math. J. 27 (1960), 251-259.

[19] C. Georgakis, The Hausdorff mean of a Fourier-Stieltjes transform, Proc. Amer. Math. Soc. 116 (1992), 465-471.

[20] G. H. HARDY, Divergent Series, Oxford University Press, Oxford (1949).

[21] F. HAusdorfF, Summation methoden und Momentfolgen, I, Math. Z. 9 (1921), 74-109.

[22] W. A. HurWitZ AND L. L. Silverman, The consistency and equivalence of certain definitions of summabilities, Trans. Amer. Math. Soc. 18 (1917), 1-20.

[23] H. D. Hung AND L. D. KY, New weighted multilinear operators and commutators of Hardy-Cesàro type, Acta Math. Sci. Ser. B Engl. Ed. 35 (2015), 1411-1425.

[24] Y. KAnjin, The Hausdorff operators on the real Hardy spaces $H^{p}(\mathbb{R})$, Studia Math. 148 (2001), $37-45$.

[25] E. LifLyAnd AND F. MóRICZ, The Hausdorff operator is bounded on the real Hardy space $H^{1}(\mathbb{R})$, Proc. Amer. Math. Soc. 128 (2000), 1391-1396.

[26] E. LifLYAND, Hausdorff operators on Hardy spaces, Eurasian Math. J. 4 (2013), 101-141.

[27] E. LifLYAND AND A. MiYACHI, Boundedness of the Hausdorff operators in $H^{p}$ spaces, $0<p<1$, Studia Math. 194 (2009), 279-292.

[28] E. Liflyand And A. MiYACHI, Boundedness of multidimensional Hausdorff operators in $H^{p}$ spaces, $0<p<1$, Trans. Amer. Math. Soc. 371 (2019), 4793-4814.

[29] A. LERNER AND E. LifLYAND, Multidimensional Hausdorff operators on real Hardy spaces, J. Austr. Math. Soc. 83 (2007), 79-86.

[30] S. Z. Lu, D. C. YANG AND G. E. Hu, Herz type spaces and their applications, Beijing Sci. Press, Beijing (2008).

[31] J. RUAN AND D. FAn, Hausdorff operators on the power weighted Hardy spaces, J. Math. Anal. Appl. 433 (2016), 31-48.

[32] S. S. Volosivets, Hausdorff operators on p-adic linear spaces and their properties in Hardy, BMO, and Hölder spaces, Math. Notes 3 (2013), 382-391.

[33] C. TAng, F. Xue And Y. Zhou, Commutators of weighted Hardy operators on Herz-type spaces, Ann. Polon. Math. 101 (3) (2011), 267-273.

[34] J. XIAO, $L^{p}$ and BMO bounds of weighted Hardy-Littlewood averages, J. Math. Anal. Appl. 262 (2001), 660-666. 